\title{
The future of eye tech
}

Published at www.cmaj.ca on Feb. 11

I $\mathrm{f}$ there is such a thing as the polar opposite of a big-screen TV, a group of Washington academics may have invented it. And it might be coming soon to an eyeball near you.

Researchers at the University of Washington in Seattle are developing bionic contact lenses, equipped with light-emitting diodes, electronic circuits and antennas. Potential uses of this technology include biochemical sensors to monitor health indicators and digital displays to watch video. In other words, you might someday be able to monitor your glucose levels while watching the Super Bowl from the comfort of your own cornea.

"We integrate small devices into unconventional places," Babak Parviz, an associate professor of electrical engineering involved in the project, says of his team of experts in nanotechnology and microfabrication.

The research is not mature, but Parviz and his colleagues have run successful tests on animals. Rabbits have worn the lenses for 20 minutes without any apparent adverse effect. The embedded electronics were not activated during these tests, however.

"Human tests are some time away," Parviz says. "This is very difficult research."

It is not so difficult, however, to imagine that many people would become fans of this technology if it is ever perfected. Video game enthusiasts could immerse themselves in digital worlds. Pilots could use bionic contact lenses to simulate flights. Soldiers could use them to simulate combat. Any person within range of a wireless Internet connection could, in the blink of an eye, check their stocks or the weather forecast or the score of a hockey game.

The contact lenses could also be equipped with sensors to monitor such things as blood pressure, cholesterol, glucose, calcium and other indicators of

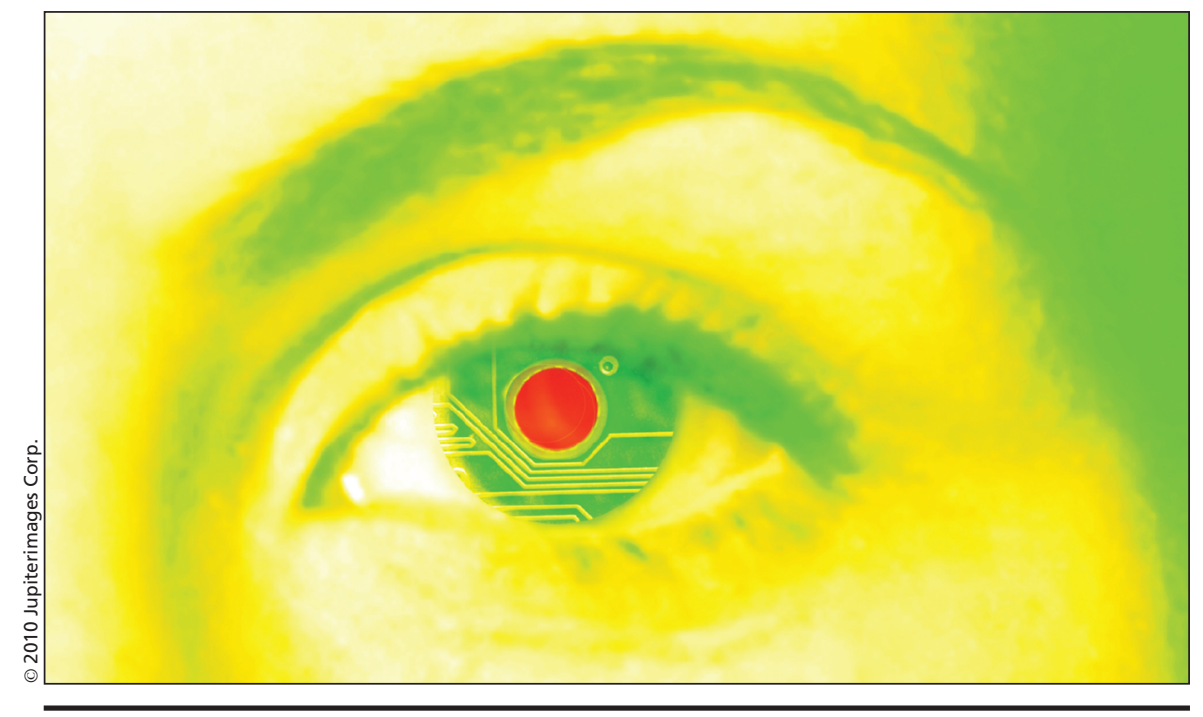

Washington researchers are developing bionic contact lenses, equipped with with light-emitting diodes, electronic circuits and antennas.

health present on the eye. That information could then be transmitted from the contact lenses to a database to be stored and later analyzed.

"People could live their normal lives while monitoring their biochemistry," says Parviz. But getting to that point, he adds, won't be easy. "The challenges are huge."

One of those challenges is building tiny circuits on materials used to make contact lenses, which have different properties than typical substrates for microchips. Parviz and his colleagues, however, have already created a unique micromanufacturing process to address that problem. Their contact lenses contain "receptor sites," each of which attracts a particular part of an electronic device. The microscopic parts float to their designated sites and self-assemble to form the final product.

Another problem is that the devices on the lenses require power to operate, like any electronic gizmo. Since squeezing a battery into the pupil is not an option, the researchers are looking at ways to convert radio waves into energy.

Some optical experts point out another big hurdle: producing clear images directly on eyes might be impossible. A human eye has difficulty focusing on objects closer than 25 centimetres. In addition, contact lenses move around on the eye and so will any images displayed on them.

"The image is going to be driving you nuts because it is constantly moving," says Guillermo Rocha, an eye surgeon at the GRMC Vision Centre in Brandon, Manitoba.

Despite the challenges, Parviz's research has attracted adequate funding and considerable interest from industry. He hopes to show that the contacts work in humans and make them available to medical researchers and, eventually, to the public.

According to Rocha, a useful medical application for electronic contact lenses might be some way off. But with advances in nanotechnology and microelectronics, he says, an interesting product could show up in the not-toodistant future.

"In the next five years, we could get something useful," Rocha says. "I'm excited about finding new ways of measuring things without invading the body." — Roger Collier, CMAJ

DOI:10.1503/cmaj.109-3181 